\title{
Towards the Improvement of Fruit-Quality Parameters in Citrus under Deficit Irrigation Strategies
}

\author{
A. Aguado, J. Frías, I. García-Tejero, F. Romero, J. L. Muriel, and N. Capote \\ IFAPA Centro Las Torres-Tomejil, Carretera Sevilla-Cazalla Km 12’2, Alcalá del Río, 41200 Sevilla, Spain \\ Correspondence should be addressed to I. García-Tejero, ivanf.garcia@juntadeandalucia.es
}

Received 8 April 2012; Accepted 18 June 2012

Academic Editors: J. B. Alvarez, L. Marton, and Z. Yanqun

Copyright ( 2012 A. Aguado et al. This is an open access article distributed under the Creative Commons Attribution License, which permits unrestricted use, distribution, and reproduction in any medium, provided the original work is properly cited.

\begin{abstract}
Water shortage is becoming a severe problem in arid and semiarid regions worldwide, reducing the availability of agricultural land and water resources. In Spain, citrus is one of the most economically important crops, with 74,000 ha devoted to its cultivation. Since water resources are increasingly more insufficient, the efficient use of water is becoming more essential. Deficit irrigation in many agricultural crops has frequently proved to be an efficient tool for improving water-use efficiency. This paper examines the effects a deficit irrigation during the ripening period on yield and the most representative fruit quality properties. The study was conducted during two consecutive years (2009-2010) in a commercial 12-year-old orange orchard (Citrus sinensis L. Osb. cv. Navelina) grafted onto Carrizo citrange (Citrus sinensis L. Osb. $\times$ Poncirus Trifoliata L. Osb.). A regulated deficit irrigation (DI) was applied, which was fully irrigated during the flowering and fruit-growth stage, and during the ripening period it was subjected to a water-stress ratio of 0.75 . A control treatment was established, this being irrigated at $100 \%$ of crop evapotranspiration. Along the water stress period, it was tested the temporal evolution of the main organoleptic and nutraceutical fruit properties (color index, the total soluble solids, titrable acidity, maturity index, rind weight, juice weight, the ratio of juice weight versus fruit weight, and the total $\mathrm{C}$ vitamin and flavonoids). It was not observed a descend in juice content, or fruit weight, or in the final yield. In terms of fruit organoleptic and nutraceutical properties, there were not detected negative effects in the studied properties. Furthermore, DI treatment showed higher values of maturity index than control treatment, which can be considered as a positive aspect in the fruit quality. Considering these results, we can affirm that a moderate water stress applied during the maturity period is a sustainable strategy for saving water, increasing the irrigation productivity and obtaining fruits with similar properties to those without deficit irrigation.
\end{abstract}

\section{Introduction}

Citrus is one of the most important crops in Andalusian agriculture, with 74,000 ha devoted to its cultivation. In the last 25 years, this surface has grown by $2.04 \%$ annually; and it has therefore been promoted that the citrus production will be close to 2.3 million tons by 2015 (30\% of the national production). Of the total area of citrus in Andalusia, 51,500 ha are dedicated to sweet orange, being the Navelina variety the second most representative of them with 13,000 ha García-Tejero [1]. Between the most limiting factors for agriculture in Andalusia are its climatic conditions, with a Mediterranean-dry climate, characterized by the irregularity and scarcity of rainfall, and a high evapotranspiration, closely to $1,600 \mathrm{~mm}$, coinciding the months with the largest evapotranspiration levels (June, July, august, and September) with those in which the rainfall are closely to zero.

Considering that water is a scarce resource in Spain, the irrigated agriculture accounting for $80 \%$ of global water consumption [2]; it is important to apply different management strategies for increasing the water-use efficiency. In this context, several contributions have documented the advantages of deficit irrigation strategies to improve the efficiency of water use and fruit quality in citrus trees: [3-9]. Shalhevet and Bielorai [10] and Doorenbos and Kassam [11] established that response of the citrus trees to water stress depends mainly on the phenological stage of the crop. Several authors have pointed out the great importance of the growth periods during which water stress is imposed, as well as the different climatic characteristics of the orchard. In this sense, 
during fruit-growth stage, a water-stress-induced results in a descend of fruit diameter, an increment in fruit drop, and a minor amount of juice per weight unit, this not being a recommendable strategy [12]. In this sense, García-Tejero et al. [13] reported that since the point of view of the irrigation water-use efficiency, it was more useful the management of limited irrigation water amounts during the ripening period, because in this case a water stress is not reflected in a decrease in the final yield, although it could be reflected in the fruitquality parameters. In this context, the quality of citrus fruit is affected by water stress due to changes in juice properties, such as increases in sugar concentration and acidity, which could reduce in some cases the fruit quality [14]. Several authors such as Ginestar and Castel [4], González-Altozano and Castel [5] or García-Tejero et al. [15] reported that total soluble solids (TSS) or titratable acidity (TA) levels are increased when a moderate water-stress is applied during the maturity period, and this fact may affect to the ratio of these characters, and hence, the time of the harvest [16]. Navarro et al. [14] argued that a moderate water-stress induced higher carbohydrates concentration in juice than unstressed plants; and this fact was independent of fruit size and juice content. In this line, it was related with the main factor involved in this change. Thus, passive dehydratation of juice sacs was not the primary cause of differences in sugar accumulation as it was stated by Barry et al. [17] or Yakushiji et al. [18] among others. Not only classical parameters such as sugar content or juice acidity are affected by water deficit. Navarro et al. [14] found significant increments in ascorbic acid content, although other authors such as Buendía et al. [19] did not find a direct relationship between deficit irrigation and the content of vitamin C.

Considering the previous researches by Pérez-Pérez et al. [20] and García-Tejero et al. [15], we hypothesised that a water-stress-induced during the ripening period can improve or keep the fruit organoleptic properties, without promoting significant descends in final yield and carrying remarkable water saving. The objective of this work was to determine the main effects of deficit irrigation when this is applied during the ripening period on the fruit quality, yield and irrigation water productivity in a commercial orchard of "Navelina" sweet orange.

\section{Material and Methods}

2.1. Experimental Site. The trial was conducted during two consecutive years (2009-2010), in a commercial 12-yearsold orchard of mature orange trees (Citrus sinensis, L. Osb. cv. Navelina) grafted onto Carrizo citrange (Citrus Sinensis, L. Osb. $\times$ Poncirus trifoliata Raf.), located in El Campillo, (Huelva), SW Spain $\left(37^{\circ} 39^{\prime} 50.15^{\prime \prime} \mathrm{N} ; 6^{\circ} 35^{\prime} 53.25^{\prime \prime} \mathrm{W}\right)$. The trees were planted spaced at $6 \times 4.5 \mathrm{~m}$ and drip irrigated by two pipe lines with pressure-compensating emitters. The average tree height was $3 \mathrm{~m}$, with a canopy diameter of $3.5 \mathrm{~m}$. The soil is an endoleptic cambisol [21], built on slate rock; with $0.6 \mathrm{~m}$ of useful deep, and roots growing predominantly within $0.4 \mathrm{~m}$ from surface. The soil is classified as a sandy loam with $0.52,0.33$ and $0.15 \mathrm{~g} \mathrm{~kg}^{-1}$ of sand, silt, and clay, respectively, with a field capacity and permanent wilting point of $0.17 \pm 0.02$ and $0.10 \pm 0.03 \mathrm{~m}^{3} \mathrm{~m}^{-3}$; and a bulk density of $1.31 \pm 0.02 \mathrm{~g} \mathrm{~cm}^{-3}$.

The local climate is Mediterranean dry, with an average potential evapotranspiration $\left(\mathrm{ET}_{0}\right)$ of $1,371 \mathrm{~mm} \mathrm{yr}^{-1}$ and annual rainfall of $780 \mathrm{~mm}$, distributed mainly from late autumn to early spring. The thermal range was broad, with average temperatures being $10^{\circ} \mathrm{C}$ in winter and $27^{\circ} \mathrm{C}$ in summer, often exceeding $40^{\circ} \mathrm{C}$ during the hours of maximum solar radiation.

2.2. Experimental Design. The experimental design was a randomized complete block, with four replicates per treatment. The experimental unit had three rows, with five trees per row, and the three central trees (central row) were established for measuring fruit properties and final yield.

A deficit-irrigation treatment (DI) was applied during the ripening period, with a water stress ratio of 0.75 , defined as the ratio between the actual water-limited supplied in this treatment versus the water supplied to control treatment. Also, a fully irrigated treatment at $100 \%$ of crop evapotranspiration $\left(\mathrm{ET}_{\mathrm{C}}\right)$ was considered as a control. Thus, in 2009 year the water-restriction period was from 301 day of the year (DOY) to harvest (322 DOY), ranging this period from 308 to 330 DOY in 2010.

The seasonal values of $\mathrm{ET}_{0}$ were determined by the modified Penman equation [22]. Climatic data were recorded at an automated weather station near the orchard, using the Doorenbos and Pruitt [23] equation for estimating the real irrigation rates required by the crop

$$
\text { Irrigation }(\mathrm{mm})=\sum_{i=1}^{7}\left[\mathrm{ET}_{0} \cdot K_{C} \cdot K_{r}\right]-\text { rain, }
$$

where $K_{C}$ is the crop coefficient, and $K_{r}$ is the reduction coefficient, calculated as twice the ratio of the shaded surface area at noon. In our case, a $K_{r}$ of 0.6 and a $K_{C}$ ranging between 0.5 from March to May, 0.55 from June to October and 0.5 in November and December, respectively.

According to this, Table 1 shows the irrigation water applied during the studied period for each treatment.

2.3. Plant Measurements and Statistical Analysis. During the studied period three different samples were established in each season $(301,315$, and 322 DOY in 2009 and $308,316,330$ DOY in 2010). For each sample there were determined 11 fruit-quality parameters, analyzing 5 fruits per tree. The external fruit colour index (CI) was measured using a tristimulus colour difference meter (Minolta CR300 colorimeter), at three locations around the equatorial plane of the fruit and two in the polar plane. The Hunter parameters $a^{*}, b^{*}$ and $L^{*}$ were reported by the colorimeter, obtaining the $\mathrm{CI}$ using the following equation:

$$
\mathrm{CI}=\frac{1000 \cdot a}{L \cdot b} .
$$

$L^{*}$ parameter gives a value of the luminance or brightness of the sample. The $a^{*}$ parameter indicates the area of 
TABLE 1: Irrigation water applied $(\mathrm{mm})$ in each treatment during the studied period.

\begin{tabular}{lcccc}
\hline & \multicolumn{3}{c}{ Year } \\
Period (DOY) & \multicolumn{2}{c}{2009} & \multicolumn{2}{c}{2010} \\
& Control & DI & Control & DI \\
\hline $1-31$ & 0 & 0 & 0 & 0 \\
$32-59$ & 7,7 & 7,7 & 0 & 0 \\
$60-90$ & 17,2 & 17,2 & 3,6 & 3,6 \\
$91-120$ & 21,4 & 21,4 & 11,4 & 11,4 \\
$121-151$ & 44,1 & 44,1 & 44,6 & 44,6 \\
$152-181$ & 70,8 & 70,8 & 65 & 65 \\
$182-212$ & 82,5 & 82,5 & 98,6 & 98,6 \\
$213-243$ & 93,5 & 93,5 & 95 & 95 \\
$244-273$ & 81 & 81 & 83 & 83 \\
$274-304^{*}$ & 72,8 & 70,4 & 56 & 56 \\
$305-334^{*}$ & 21,4 & 15,6 & 20 & 14,6 \\
$335-365$ & 0 & 0 & 0 & 0 \\
\hline Total & 512,4 & 504,2 & 477,2 & 471,8 \\
\hline
\end{tabular}

DOY: day of the year; Control: control treatment; DI: deficit irrigation treatment; * periods in which DI was applied.

variation between red and green spectrum; $b^{*}$ parameter is referred to the area of variation between yellow and blue spectrum.

The content of total soluble solids (TSS) in the juice was measured with a refractometer, and titrable acidity (TA) was determined by titration with $\mathrm{NaOH}$ and phenolphthalein indicator in $100 \mathrm{~mL}$ of juice. Maturity index (MI) was expressed as the relation TSS/TA. Rind weight (RW), juice weight (JW), and the ratio of juice weight versus fruit weight (JR) were determined using a digital scale with a precision of $\pm 0.01 \mathrm{~g}$. Total $\mathrm{C}$ vitamin (C-vit) and total flavonoids (TF) were determined by liquid chromatography (HPLC), expressed as $\mathrm{mg}$ of ascorbic acid and $\mathrm{mg}$ of hesperidin in $100 \mathrm{~mL}$ of juice, respectively.

At harvest, fruit yield was determined for each tree by weighing the orange fruits. One sample of 100 fruits per tree was collected to determine average fruit weight.

An exploratory and descriptive analysis was made of yield and its components, followed by an analysis of variance (ANOVA) with a mean separation analysis applying a Tukey's test. SPSS statistical software package was used (SPSS 15.2 for Windows, 2006, SPSS Inc., Chicago, IL).

\section{Results and Discussion}

3.1. Fruit Yield and Irrigation Water Productivity. There was no clear response of the tree yield related to deficit irrigation (Figure 1). During 2009, there was a yield reduction in DI treatment nearly to $5 \%$, this not being considered statistically significant. Additionally, during 2010, the highest values were recorded in stressed treatment, with an increment closely to $30 \%$. Newly, this difference was not statistically significant. Velez et al. [24] were unable to detect any significant differences in either the final production or the fruit weight or in the number of fruits per tree, in response to a DI

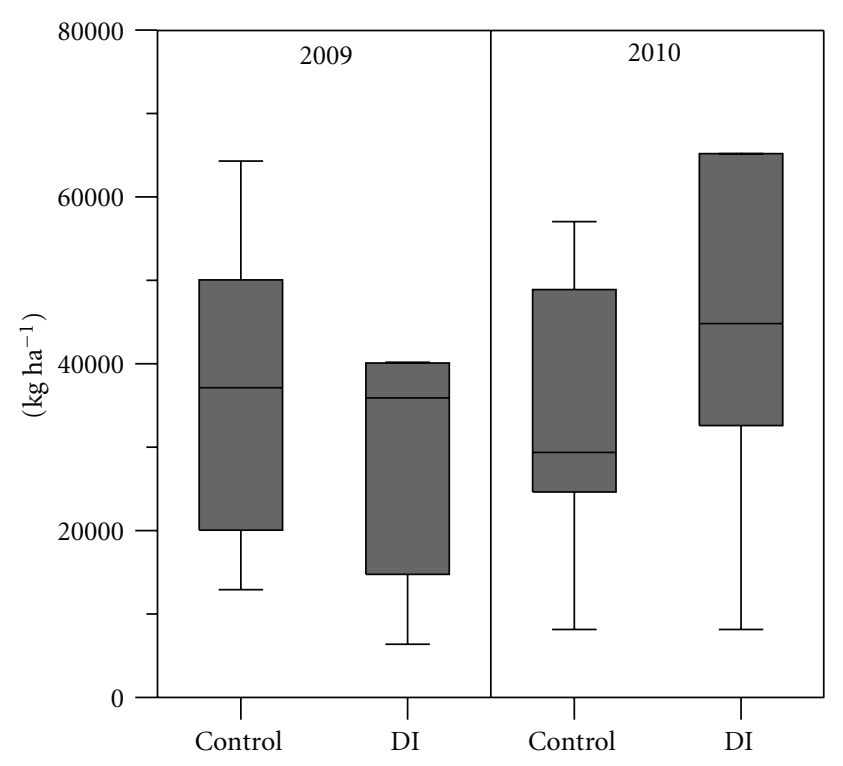

FIGURE 1: Effects of deficit irrigation on yield. Control, control treatment fully irrigated at $100 \% \mathrm{ET}_{\mathrm{C}} ; \mathrm{DI}$, deficit irrigation treatment. Vertical lines represent the error bars in each treatment.

strategy of cultivation in "Clementine of Nules," when water stress was applied during the maturity period.

In our case, the DI strategy imposed in this experience did not show significant effects on yield, further more, there was not observed an accumulative effect of water stress in subsequent years, and in the second year DI showed a higher yield, with an increment of $11,000 \mathrm{~kg} \mathrm{ha}^{-1}$. These results are in line with those showed by García-Tejero et al. [13], although these differences cannot be considered significantly different, in economic terms, this improvement in favour of deficit irrigation strategy is important enough to be taken into account by the farmer. These results are in line with those reported by Pérez-Pérez et al. [20] and Castel and Buj [25]. The first of them did not evidence significant effects of deficit irrigation in "lane late" sweet orange when water stress was imposed during the third phase of fruit growth, whereas the second did not find significant yield reduction when water stress was applied in the ripening period in sweet orange cv. "Salustiana".

The lack of effects of DI on final yield along with the water savings promoted increments on irrigation water productivity, this being especially remarkable during 2010 year (Figure 2). The fact was due to the major yields values in DI during this year. Normally, when water is withheld, it causes a yield drop and increases in water productivity. When water stress is considered severe, production drastically declines, decreasing water productivity to some extent. An amount of water applied at different phenological periods can increase water productivity, based on the distribution throughout the irrigation periods [15].

Increasing crop-water productivity may be a means of achieving efficient and effective water use. In agriculture, the interest is to produce more with less water, because available water for irrigated land is a limiting factor in 


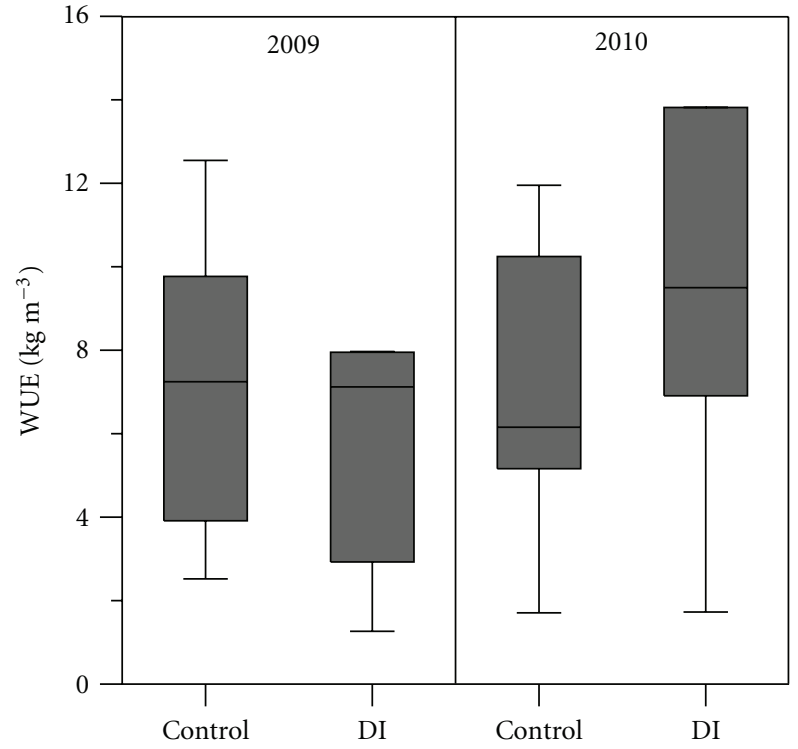

FIGURE 2: Irrigation water productivity in each treatment during the studied period. Control, control treatment fully irrigated at $100 \%$ $\mathrm{ET}_{\mathrm{C}}$; DI, deficit irrigation treatment. Vertical lines represent the error bars in each treatment.

many world areas [26]. Strategies such as DI have shown that water productivity (WP) can be enhanced $[27,28]$ and could be associated with acceptable commercial production. Nowadays, the low importance given to improving WP must be related to the reduced water costs in Mediterranean agricultural areas [29], where water represents only less than $10 \%$ of the total production costs, a clear contradiction with the Common Agricultural Policy and the water Framework Directive [30].

\subsection{Impact on Fruit-Quality Parameters. Figure 3 shows the} main effects of deficit irrigation in fruit size components. The obtained results evidence non significant effects of water stress in considered parameters. In this context, during 2009 DI treatment did not reflect descends in fruit size and juice weight (Figures 3(a) and 3(b)) . Furthermore, this treatment gave better results in these parameters, with increases in fruit and juice weight of 17 and $21 \%$, respectively, with respect to control, although higher values in the ratio between juice and fruit weight in DI with respect to control were not observed (Figure 3(c)). These results evidence larger fruits in DI than control, which is consistent with the observed results of rind weight for each treatment (Figure 3(d)).

During 2010, the obtained results are in line with those in the previous year. There were non significant differences in any parameter, although, again, there were observed increases in juice weight in DI (Figure 3(f)) but fruit weight values between treatments were very similar (Figure 3(e)). This fact promoted larger values of the ratio between juice and fruit weight in DI (a 15\% higher), which is particularly remarkable in fruits intended for juice industrial extraction (Figure 3(g)).
On overall, these results argued that a moderate waterstress during the ripening period does not promote negative effects on fruit size and juice content, this stage being a good time for introduce water savings and maintain an optimum fruit development. Ballester et al. [31] did not find significant effects on fruit weight when a moderate water stress was applied during three different stages in "Clementina de Nules." However, other authors such as González-Altozano and Castel [32] in this same cultivar argued that a water stress at the end of summer-autumn could reduce the fruit weight, decreasing the commercial value of them.

Figure 4 shows the main effects of deficit irrigation in fruit quality parameters. The obtained results evidence no significant effects of water stress in considered parameters. In this context, during 2009 DI treatment did not reflected increments in TSS (Figure 4(a)) and TA (Figure 4(b)), fact that also could be observed during the 2010 year (Figures 4(d) and 4(e)). However the ratio between TSS and TA (expressed as MI) was higher in DI treatment during 2009 year (Figure 4(c)). Although this increment was not statistically significant, an increase of MI is considered as a positive point for the commercial value of juice, and advantage an early harvest in sweet orange varieties such as Navelina.

Many studies have been pointed out that water stress in citrus crops affects these properties [15, 33-35]. Verreynne et al. [36] reported that a conventional deficit irrigation strategy with water savings of $60-66 \%$ in relation to a control treatment, increased total soluble solids and titrable acidity in "Marisol" Clementines without affecting the juice content or reducing the fruit size. In this line, García-Tejero et al. [13] reported that a severe water stress during the fruit growth and maturity period promoted significant increase in total soluble solids and titrable acidity in different DI strategies such as sustained deficit irrigation and low-frequency deficit irrigation, but these increments are followed by a decrease in maturity index. Moreover, this decline cannot be considered as a positive effect, due to the preservation of equilibrium between the levels of sugars and juice acidity being essential to maintain the juice quality destined for industry. Similar results were reported by Treeby et al. [37] in navel orange, where deficit-irrigation treatments raised total soluble solids and titrable acidity values. In addition, Romero et al. [38] found that severe deficit irrigation raise titrable acidity more than total soluble solids, affecting the final maturity index. The opposite effect was observed in our results and may be related to the water-stress level, duration, and strategy. In this context, Pérez-Pérez et al. [20], studying "lane late" sweet orange found that when water stress was applied during the phase III of fruit growth, there was an increase of total soluble solids and titrable acidity values, although maturity index was not affected. In relation to these results, the total soluble solids content is one of the parameters most affected by a severe water stress. The main cause is not clear, although some authors have explained that this fact can be promoted by a passive dehydratation of juice sacs, accompanied by lower juice content [20].

Finally, the effects of DI during the ripening period in the temporal evolution of external colour index were studied. 


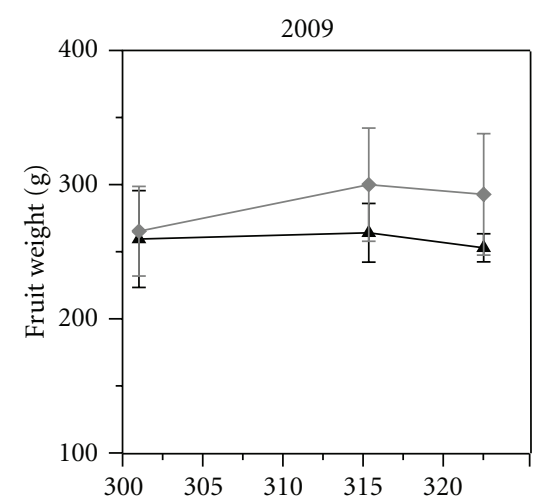

(a)

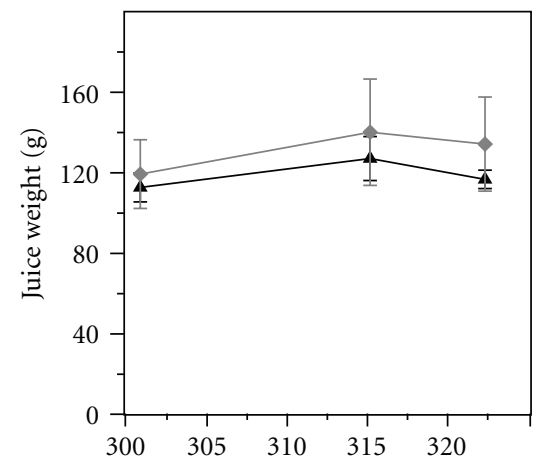

(b)

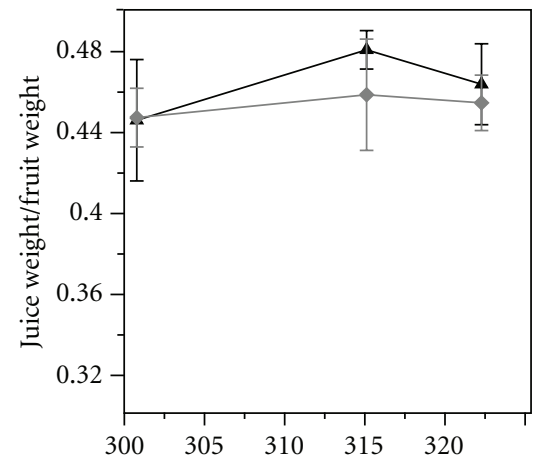

(c)

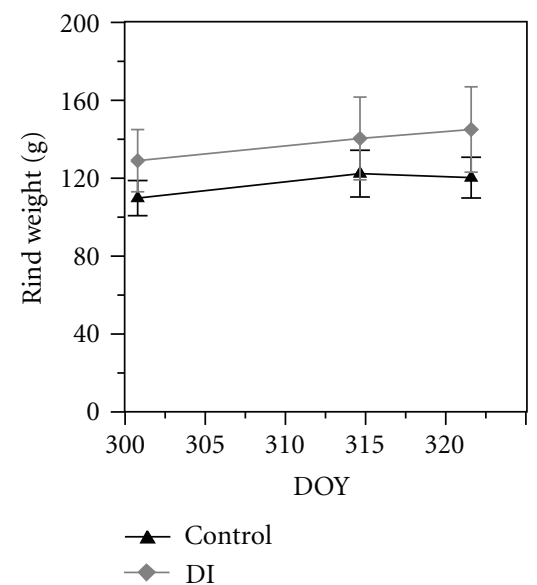

(d)

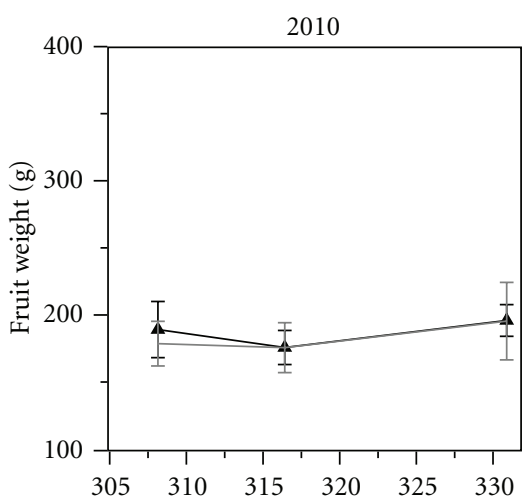

(e)

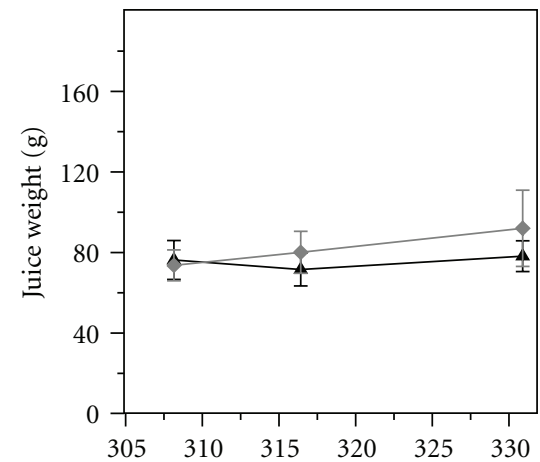

(f)

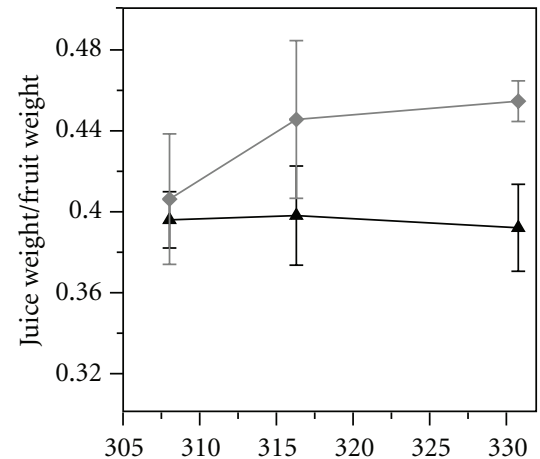

(g)

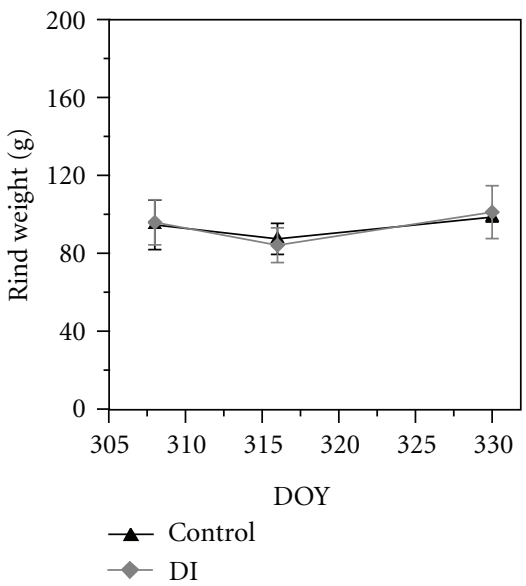

(h)

FIGURE 3: Timing evolution of fruit size components. Control, control treatment; DI, deficit irrigation. Vertical lines represent the error bars in each treatment. 

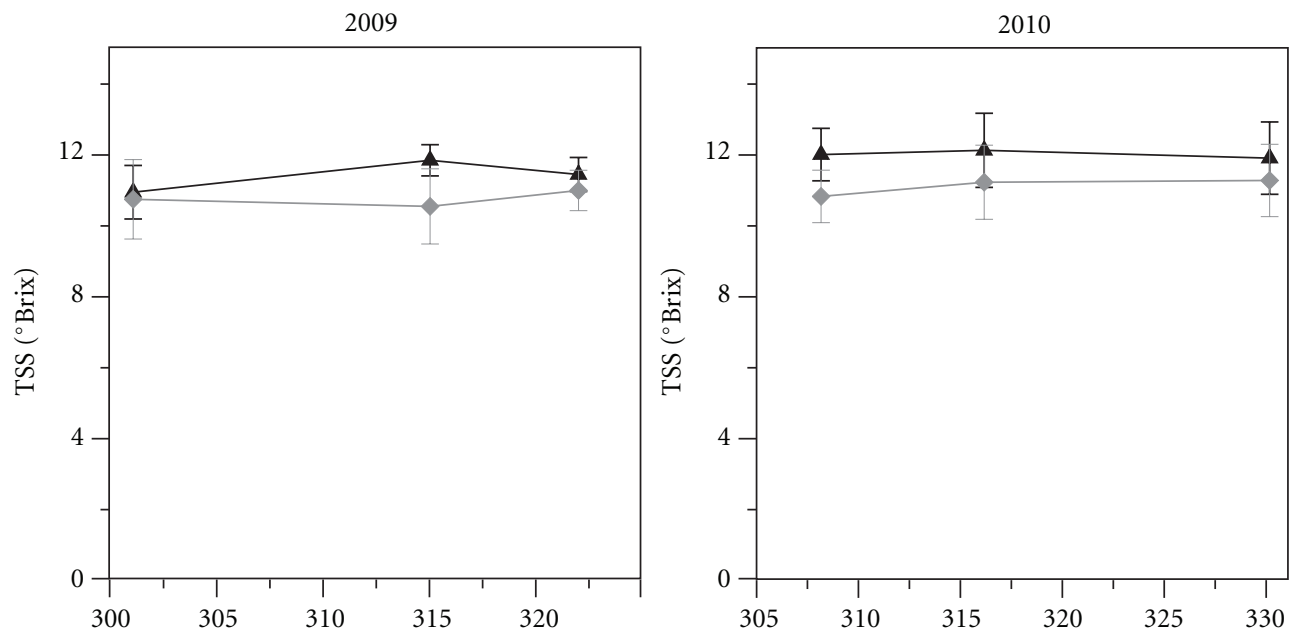

(a)

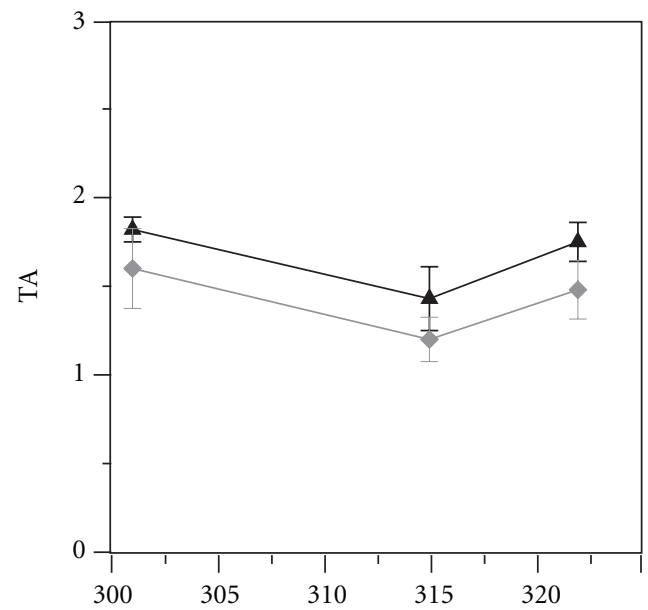

(d)

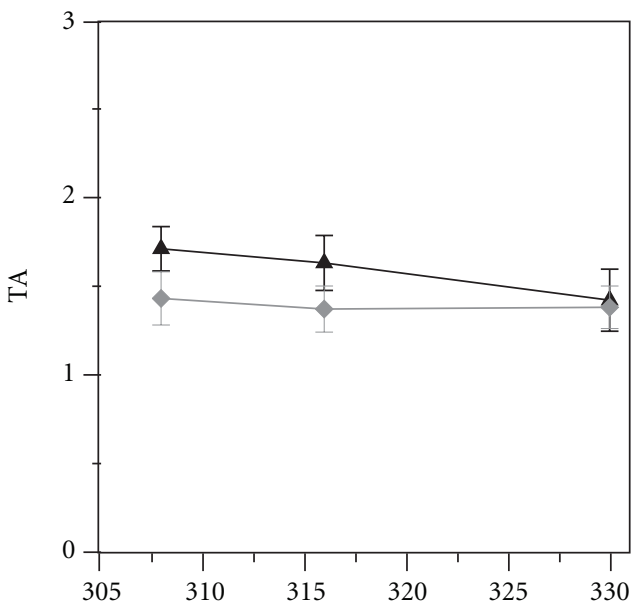

(b)

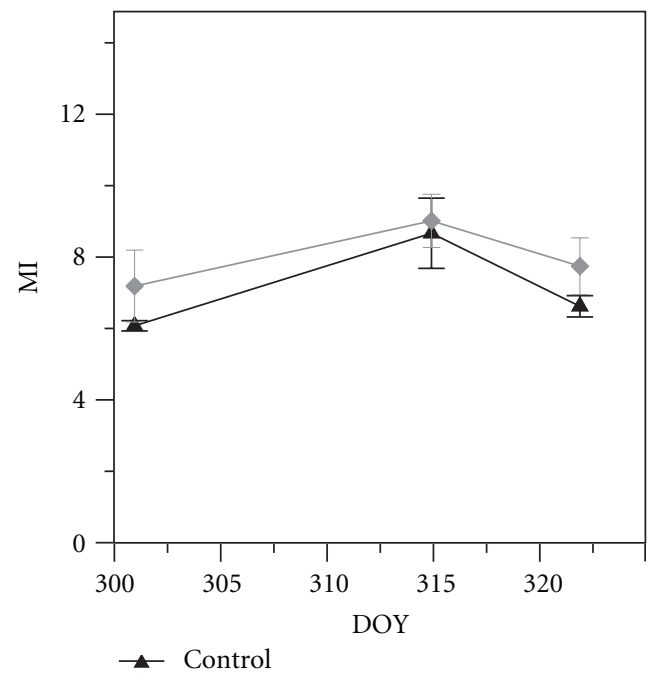

(e)

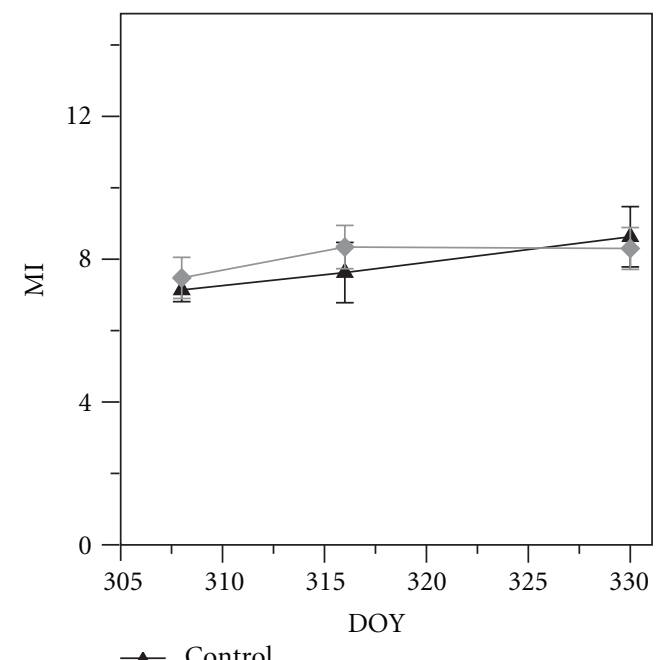

$\leftrightarrow$ DI

$\rightarrow$ Control

(c)

(f)

FIgURE 4: Timing evolution of fruit quality parameters. Control, control treatment; DI, deficit irrigation; TSS, total soluble solids; TA, titrable acidity; MI, maturity index. Vertical lines represent the error bars in each treatment. 


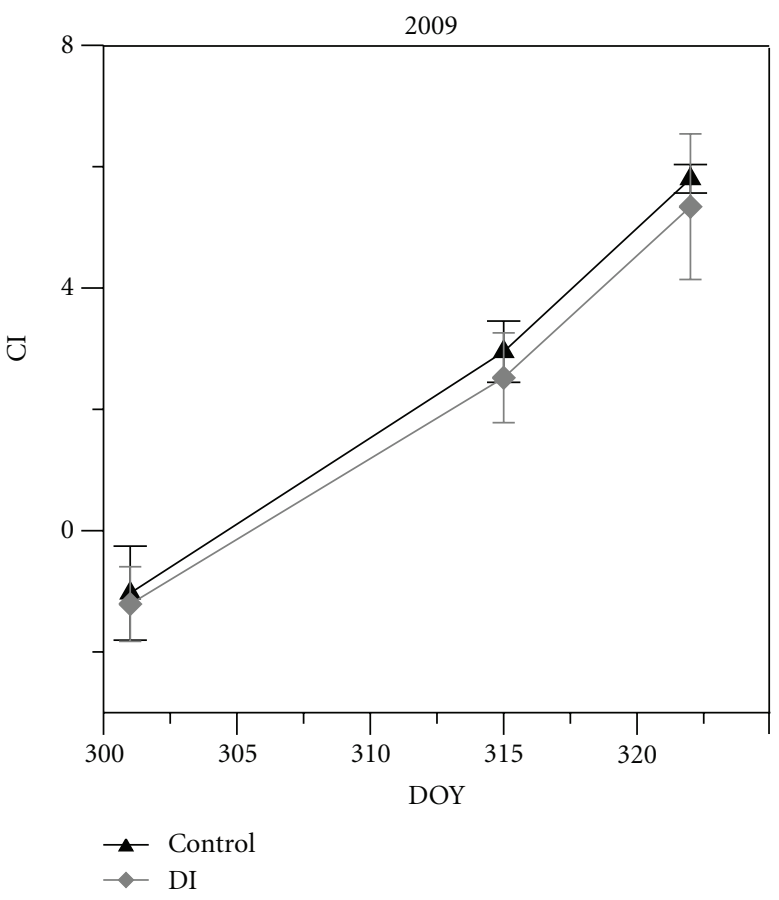

(a)

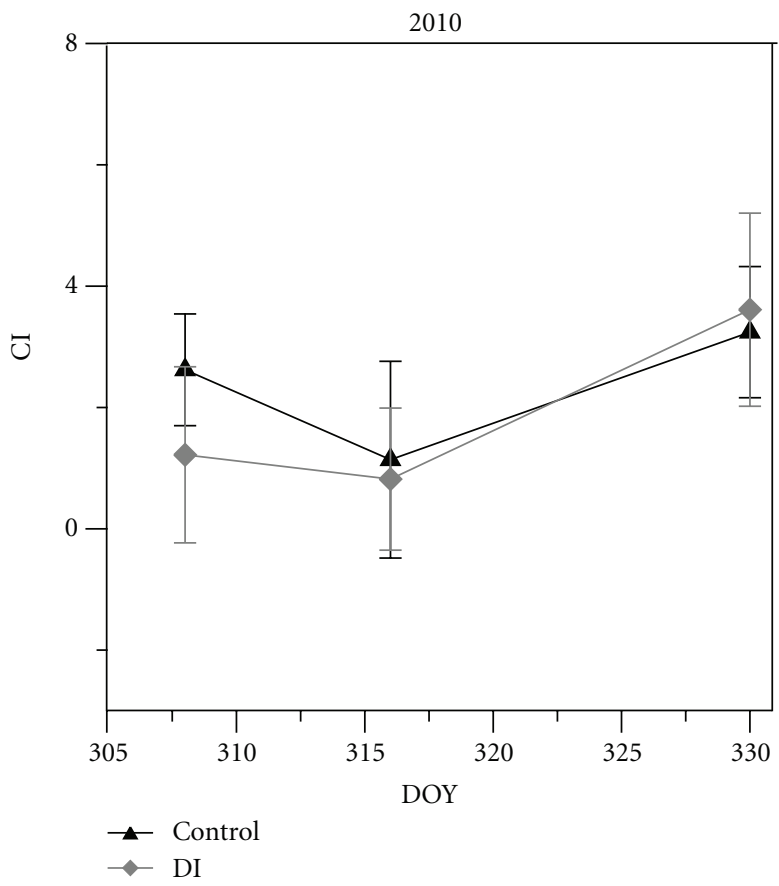

(b)

FIGURE 5: Effects of deficit irrigation on colour index (CI) during 2009 (a) and 2010 year (b). Vertical lines represent the error bars in each treatment.

The obtained results did not show significant differences between treatments (Figure 5). According to Rodrigo et al. [39], during ripening period peel colour changes fast, so that a massive accumulation of carotenoids occurs, from the transformation of chloroplasts to chromoplasts. Navarro et al. [14] argued that a water stress during the fruit growth stage could promote a delay in maturation process. In this same line, if water stress was applied during ripening period, this process occurs in a similar way to full-irrigated treatment.

3.3. DI and Nutraceutical Properties. In recent years research activities in agriculture have been aimed to find new production strategies for improving the foods nutraceutical properties. Among the possibilities for improving the quality of them are those designed to achieve an increase in the components recognized as healthy. In this sense, Flavonoids and vitamin $\mathrm{C}$ are highly beneficial antioxidant compounds found in many fruits and vegetables, and it's now well established that a plentiful intake of antioxidants through foods, drinks and supplements is vital for optimal human health. It has been recognized that orange juice is an important source of vitamin $\mathrm{C}$ and hesperidin for human nutrition. In this sense, we have tried to address a study on the effects of deficit irrigation in the synthesis of these compounds. In line with the previous results, there were no detected significant differences between treatments during the monitoring period. In this sense, moderate deficit irrigation during the ripening period was not reflected with a decrease in the ascorbic acid (Figure 6(a)) and herperidin contents (Figure 6(b)).

Navarro et al. [14] showed that DI during stage II of fruit growth promoted significant increments of ascorbic acid with respect to the control juice. They argued that these values could be due to a more pronounced synthesis of vitamin $\mathrm{C}$ in response to water stress and/or to the lower fruit water content. If this were true, decreases in juice content would have been detected. These authors did not find significant differences in the contents of ascorbic acid when water stress was applied during phase III of fruit growth, also reflecting higher juice contents in this treatment compared with control treatment. Comparing these results with those obtained in this work, the absence of significant differences would be related with the higher juice contents detected in DI treatment. As similar effects were detected in hesperidin content, this behavior may be due to the same reason that the contents of ascorbic acid.

\section{Conclusions}

According to the results of the present study, we have not been able to prove that a moderate water stress during the ripening period in sweet orange citrus trees induce a deterioration of fruit quality properties. In this sense, a descend in juice content and in fruit weight was not observed. This fact supports the obtained results on final yield, which was not affected by deficit irrigation, even with an increase on yield values of deficit irrigation. 


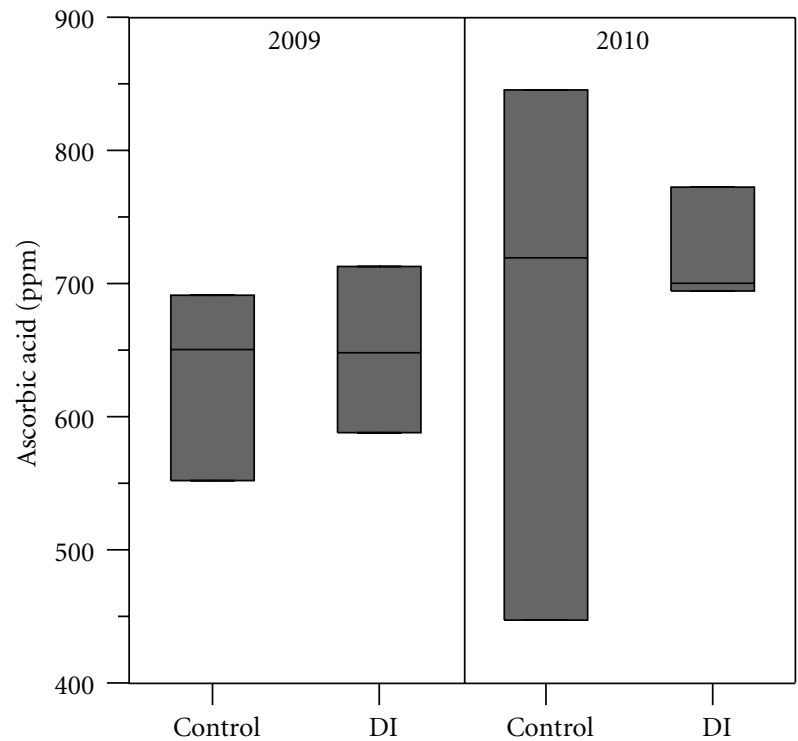

(a)

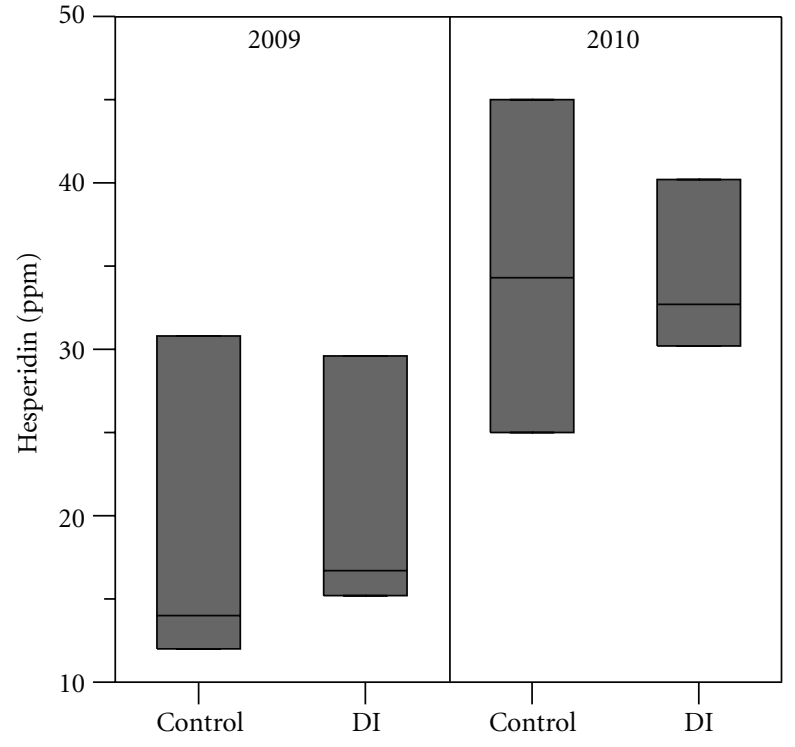

(b)

FIGURE 6: Effects of deficit irrigation on ascorbic acid (a) and hesperidin contents (b). Control, control treatment; DI, deficit irrigation treatment. Vertical lines represent the error bars in each treatment.

In terms of fruit organoleptic and nutraceutical properties, there were not detected pernicious effects on them. Moreover, DI treatment showed higher values of maturity index due to the keeping of ratio between the contents of total soluble solids and titrable acidity.

Considering these results, we can affirm that a moderate water stress applied during the last fruit-growth period is a sustainable strategy for saving water, increasing the irrigation productivity and obtaining fruits with similar properties to those without deficit irrigation.

\section{Acknowledgments}

The authors thank Antonio Caballero for his excellent technical support as personal of Rio Tinto Fruit S.L., where experimental assay has been development. This work was supported by funds from the Project between IFAPA and the Companies Arvensis Agro S.A (CAICEM 09-46), Cultifort S.L. (CC09-009), and Sustineable Agro Solutions S.A. (CEM 09-009).

\section{References}

[1] I. García-Tejero, Deficit irrigation for sustainable citrus cultivation in Guadalquivir river basin [Ph.D. thesis], Universidad de Sevilla, 2010.

[2] MAPA, "Plan Nacional de Regadíos," Horizonte 2008. MAPA. Gobierno de España, 2008.

[3] A. Southwick and T. L. Davenport, "Characterization of water stress and low temperature effects on flower induction in citrus," Plant Physiology, vol. 81, pp. 26-29, 1986.

[4] C. Ginestar and J. R. Castel, "Responses of young clementine citrus trees to water stress during different phenological periods," Journal of Horticultural Science and Biotechnology, vol. 71, no. 4, pp. 551-559, 1996.
[5] P. González-Altozano and J. R. Castel, "Effects of regulated deficit irrigation on "Clementina de Nules" citrus trees. I. Yield and fruit quality effect," Journal of the American Society for Horticultural Science, vol. 74, no. 6, pp. 706-713, 1999.

[6] P. González-Altozano and J. R. Castel, "Effects of regulated deficit irrigation on "Clementina de Nules" citrus trees. II. Vegetative growth," Journal of the American Society for Horticultural Science, vol. 75, no. 4, pp. 388-392, 2000.

[7] J. L. Muriel, J. A. Jiménez, I. García-Tejero, and I. Vaquero, "Relaciones hídricas en una plantación de naranjos (Citrus Sinensis, L. Cv Navelino) bajo estrategias de riego deficitario mantenido," in VIII Simposium Hispano Portugués de Relaciones Hidricas en las Plantas, D. Morales-Méndez and M. S. Jiménez-Parrondo, Eds., pp. 139-142, Tenerife, Spain, 2006.

[8] I. García-Tejero, J. A. Jiménez, J. L. Muriel, and G. Martínez, "Planificación y desarrollo de estrategias de riego deficitario en una plantación de naranjos: influencia de la variabilidad espacial de las propiedades del suelo," in Book of Abstracts, Congreso Nacional de Riegos, Pamplona, Spain, 2007.

[9] I. García-Tejero, J. A. Jiménez, M. C. Reyes, A. Carmona, R. Pérez, and J. L. Muriel, "Aplicación de caudales limitados de agua en plantaciones de cítricos del valle del Guadalquivir," Fruticultura Profesional, vol. 173, pp. 5-17, 2008.

[10] J. Doorenbos and A. Kassam, "Yield response to water," FAO Irrigation and drainage. Paper no. 33. FAO Rome, Italy, 1979.

[11] J. Shalhevelt and H. Bielorai, "Crop water requirements in relation to climate and soil," Soil Science, vol. 125, pp. 240-247, 1978.

[12] I. García-Tejero, V. H. Durán-Zuazo, J. Arriaga, and J. L. Muriel-Fernández, "Impact of deficit irrigation on citrus yield," Agronomy for Sustainable Development, vol. 32, no. 3, pp. 651-659, 2012.

[13] I. García Tejero, V. H. Durán, J. A. Jiménez, and J. L. Muriel, "Improved water-use efficiency by deficit-irrigation programmes: implications for saving water in citrus orchards," Scientia Horticulturae, vol. 128, no. 3, pp. 274-282, 2011. 
[14] J. M. Navarro, J. G. Pérez-Pérez, P. Romero, and P. Botía, "Analysis of the changes in quality in mandarin fruit, produced by deficit irrigation treatments," Food Chemistry, vol. 119, no. 4, pp. 1591-1596, 2010.

[15] I. García-Tejero, R. Romero, J. A. Jiménez, G. Martínez, V. H. Durán, and J. L. Muriel, "Response of citrus trees to deficit irrigation during different phenological periods in relation to yield, fruit quality, and water productivity," Agricultural Water Management, vol. 97, no. 5, pp. 614-622, 2010.

[16] P. L. Harding, J. R. Winston, and D. F. Fisher, Seasonal Changes in Florida Grapefruit, vol. 886, USDA Technical Bulletin, Washington, DC, USA, 1940.

[17] G. H. Barry, W. S. Castle, and F. Davies, "Rootstocks and plant water relations affect sugar accumulation of citrus fruit via osmotic adjustment," Journal of the American Society for Horticultural Science, vol. 129, no. 6, pp. 881-889, 2004.

[18] H. Yakushiji, H. Nonami, T. Fukuyama, S. Ono, N. Takagi, and Y. Hashimoto, "Sugar accumulation enhanced by osmoregulation in Satsuma mandarin fruit," Journal of the American Society for Horticultural Science, vol. 121, no. 3, pp. 466-472, 1996.

[19] A. Buendía, A. Allende, E. Nicolás, J. J. Alarcón, and M. I. Gil, "Effect of regulated deficit irrigation and crop load on the antioxidant compounds of peaches," Journal of Agricultural and Food Chemistry, vol. 56, no. 10, pp. 3601-3608, 2008.

[20] J. G. Pérez-Pérez, J. M. Robles, and P. Botía, "Influence of deficit irrigation in phase III of fruit growth on fruit quality in 'lane late' sweet orange," Agricultural Water Management, vol. 96, no. 6, pp. 969-974, 2009.

[21] FAO, World Reference Base for Soil Resources, Rome, Italy, Food and Agriculture Organization of the United Nations, 1998.

[22] R. G. Allen, L. S. Pereira, D. Raes, and M. Smith, "Crop evapotranspiration (Guidelines for computing crop water requirements)," FAO Irrigation and Drainage Paper no. 56, FAO, Rome, Italy, 1998.

[23] J. Doorenbos and W. O. Pruitt, "Crop water requirements," FAO Irrigation and Drainage paper no. 24, FAO Rome, Italy, 1977.

[24] J. E. Velez, D. S. Intrigliolo, and J. R. Castel, "Scheduling deficit irrigation of citrus trees with maximum daily trunk shrinkage," Agricultural Water Management, vol. 90, no. 3, pp. 197-204, 2007.

[25] J. R. Castel and A. Buj, "Response of salustiana oranges to high frequency deficit irrigation," Irrigation Science, vol. 11, no. 2, pp. 121-127, 1990.

[26] M. H. Ali and M. S. U. Talukder, "Increasing water productivity in crop production-a synthesis," Agricultural Water Management, vol. 95, no. 11, pp. 1201-1213, 2008.

[27] M. H. Ali, M. R. Hoque, A. A. Hassan, and M. A. Khair, "Effects of deficit irrigation on yield, water productivity, and economic returns of wheat," Agricultural Water Management, vol. 92, no. 3, pp. 151-161, 2007.

[28] S. K. Jalota, A. Sood, G. B. S. Chahal, and B. U. Choudhury, "Crop water productivity of cotton-wheat system as influenced by deficit irrigation, soil texture and precipitation," Agricultural Water Management, vol. 84, no. 1-2, pp. 137-146, 2006.

[29] I. J. Lorite, L. Mateos, and E. Fereres, "Evaluating irrigation performance in a Mediterranean environment: I. Model and general assessment of an irrigation scheme," Irrigation Science, vol. 23, no. 2, pp. 77-84, 2004.
[30] M. García-Vila, I. J. Lorite, M. A. Soriano, and E. Fereres, "Management trends and responses to water scarcity in an irrigation scheme of Southern Spain," Agricultural Water Management, vol. 95, no. 4, pp. 458-468, 2008.

[31] C. Ballester, J. Castel, D. S. Intrigliolo, and J. R. Castel, "Response of clementina de nules citrus trees to summer deficit irrigation. Yield components and fruit composition," Agricultural Water Management, vol. 98, no. 6, pp. 1027-1032, 2011.

[32] P. González-Altozano and J. R. Castel, "Riego deficitario controlado en 'Clementina de Nules'. I. Efectos sobre la producción y la calidad de la fruta," Spanish Journal of Agricultural Research, vol. 1, pp. 81-92, 2003.

[33] H. Bielorai, "The effect of partial wetting of the root zone on yield and water use efficiency in a drip-and sprinkler-irrigated mature grapefruit grove," Irrigation Science, vol. 3, no. 2, pp. 89-100, 1982.

[34] I. García-Tejero, J. A. Jiménez, G. Martínez, R. Romero, V. H. Durán, and J. L. Muriel, "Positive impact of regulated deficit irrigation on yield and fruit quality in a commercial citrus orchard (Citrus sinensis (L.) Osbeck, cv. Salustiano)," Agricultural Water Management, vol. 97, no. 5, pp. 689-699, 2010.

[35] B. R. Hockema and E. Etxeberria, "Metabolic contributors to drought-enhanced accumulation of sugars and acids in oranges," Journal of the American Society for Horticultural Science, vol. 126, no. 5, pp. 599-605, 2001.

[36] J. S. Verreynne, F. Rabe, and K. I. Theron, "The effect of combined deficit irrigation and summer trunk girdling on the internal fruit quality of 'Marisol' Clementines," Scientia Horticulturae, vol. 91, no. 1-2, pp. 25-37, 2001.

[37] M. T. Treeby, R. E. Henriod, K. B. Bevington, D. J. Milne, and R. Storey, "Irrigation management and rootstock effects on navel orange [Citrus sinensis (L.) Osbeck] fruit quality," Agricultural Water Management, vol. 91, no. 1-3, pp. 24-32, 2007.

[38] P. Romero, J. M. Navarro, P. J. G. Pérez et al., "Deficit irrigation and rootstock: their effects on water relations, vegetative development, yield, fruit quality and mineral nutrition of Clemenules mandarin," Tree Physiology, vol. 26, no. 12, pp. 1537-1548, 2006.

[39] M. J. Rodrigo, J. F. Marcos, and L. Zacarías, "Biochemical and molecular analysis of carotenoid biosynthesis in flavedo of orange (Citrus sinensis L.) during fruit development and maturation," Journal of Agricultural and Food Chemistry, vol. 52, no. 22, pp. 6724-6731, 2004. 


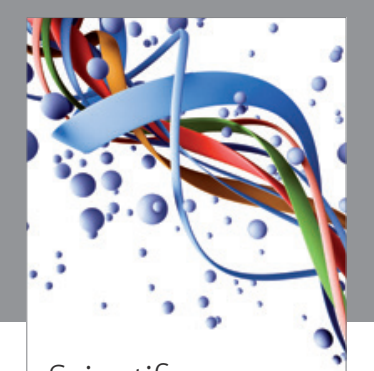

Scientifica
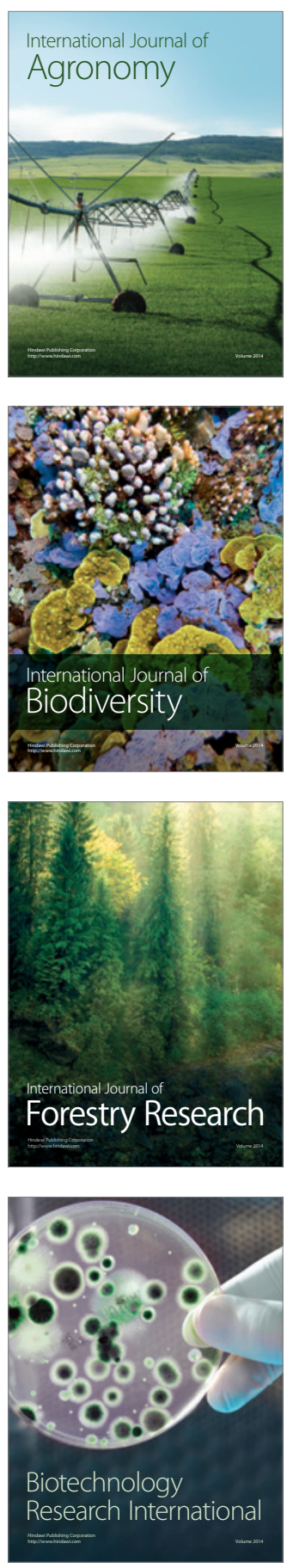
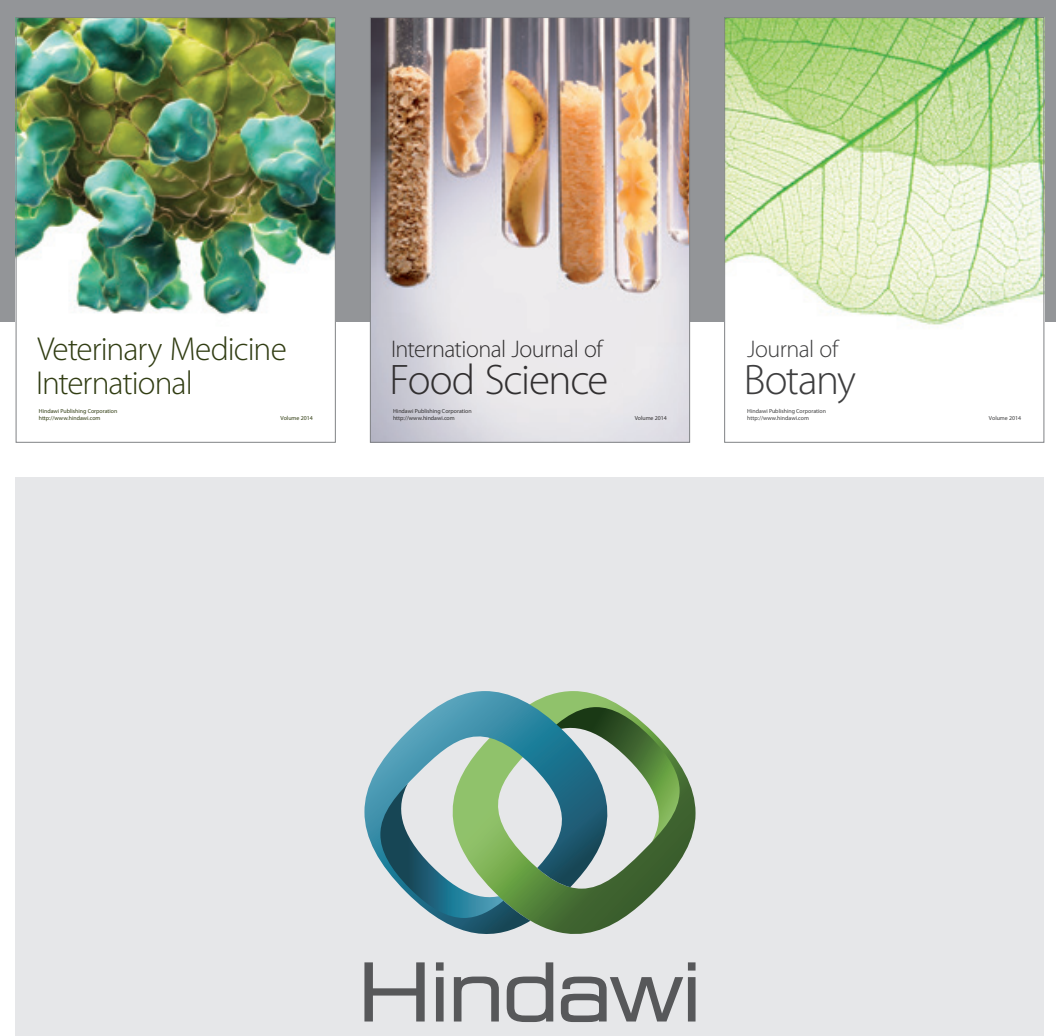

Submit your manuscripts at

http://www.hindawi.com
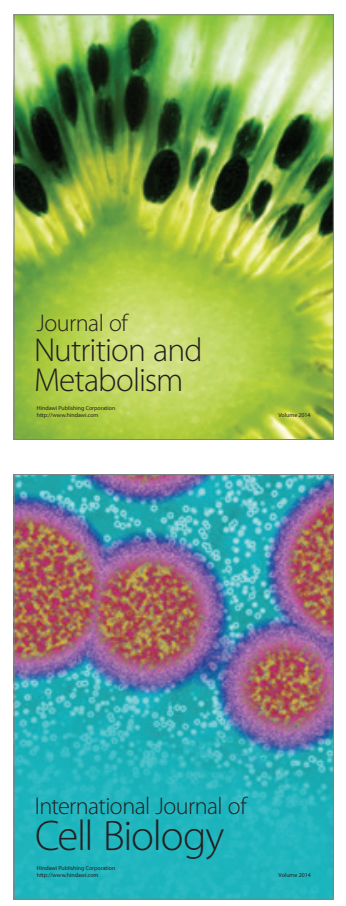
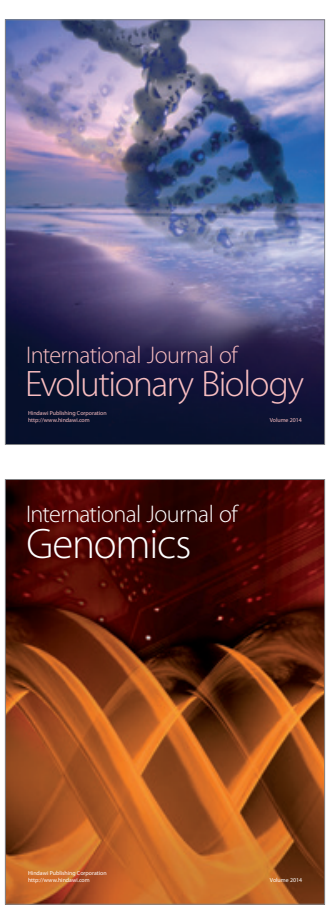
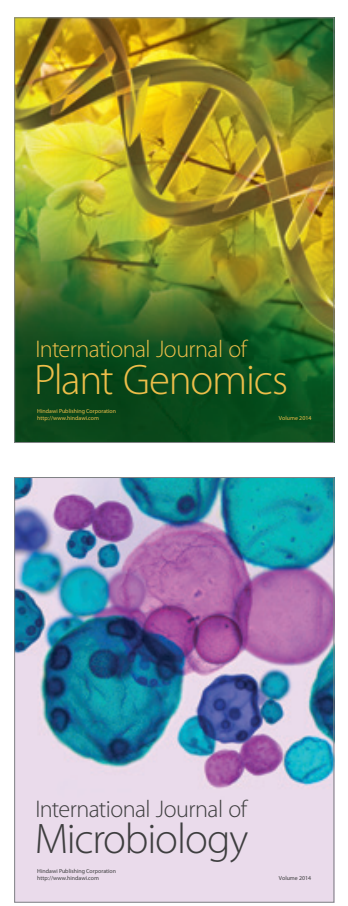

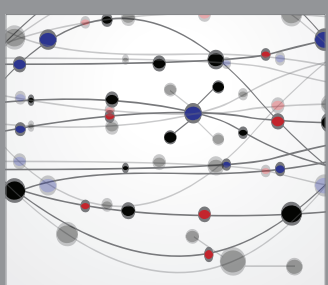

The Scientific World Journal
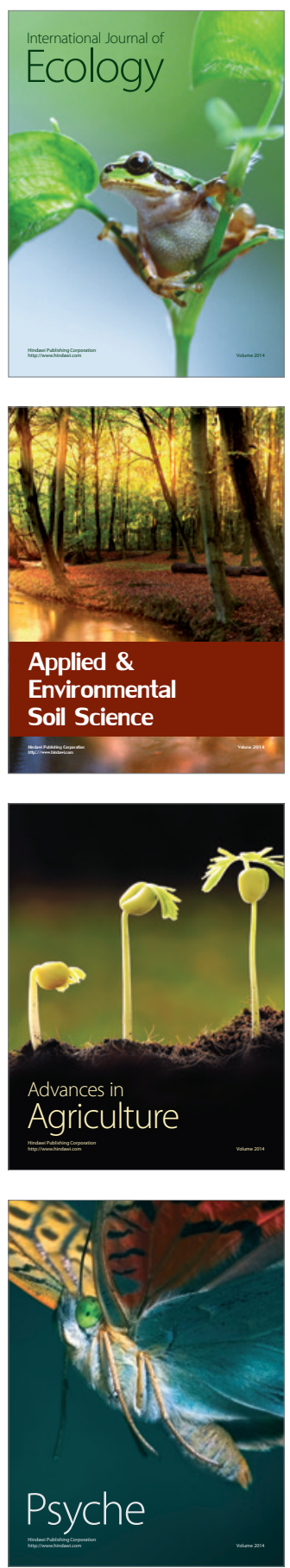